\title{
ORDENAMENTO TERRITORIAL NA ILHA DO ATALAIA, SALINÓPOLIS (PA): UMA ANÁLISE A PARTIR DOS DIFERENTES TRECHOS DE OCUPAÇÃO
}

\author{
Geisa Bethânia Nogueira de SOUZA1 \\ Gilberto de Miranda ROCHA
}

\section{Resumo}

O processo de apropriação e ocupação da Ilha do Atalaia, no Município de Salinópolis, Estado do Pará, influenciou a atuação de diversificados atores sociais cuja produção de processos espaciais se estruturam de forma também diferenciada, o que ocasionou novas relações sociais fundamentadas na reprodução desigual e desproporcional do espaço.A metodologia utilizada para a produção deste artigo foi baseada em análise documental, observação, entrevistas semiestruturadas com atores sociais locais e profissionais especializados e construção de carta-imagem e mapa.Os resultados da pesquisa demonstram que as formas espaciais criadas por seus atores sociais ao longo do processo de produção do espaço, podem ser constatadas nos diferentes trechos de ocupação da Ilha. Portanto, as dinâmicas sociais e ambientais também acompanham as especificidades encontradas em cada trecho,os quais exigem tipos diferentes de análise e a gestão deve acompanhar essas particularidades.

Palavras-chaves: atores sociais, produção do espaço, trechos de ocupação.

\begin{abstract}
The process of appropriation and occupation of the Island of Atalaia, in the Municipality of Salinópolis, Pará state, influenced the diversified social actors whose production of spatial processes are structured in a different form, caused new social relations based on the disproportionate reproduction of space. The methodology used to produce this article was basedon documental analysis, observation, semi-structured interviews with local social actors and specialised professionals and also elaboration of drat-images and maps. The results of the survey show that the spatial forms created by their social actors can be seen in the different stretches of occupation zones. The social and environmental dynamics accompany the specificities of each zone, which require different types of management.
\end{abstract}

Key-words: social actors, production of space, occupation zones

\section{INTRODUÇÃO}

A zona costeira é um espaço peculiarmente dinâmico com características naturais em constante alteração, cujo processo de apropriação ocasiona o aumento da utilização de seus recursos e uso desorganizado, desconsiderando a complexidade e as especificidades litorâneas, contrariando, desta maneira, a legislação vigente.

\footnotetext{
Universidade Federal do Pará. Email: geisanog@yahoo.com.br Universidade Federal do Pará. Email: 
Assim, o espaço litorâneo tem sido submetido à intensa pressão exercida pelas diversificadas formas de ocupação e uso do solo que, junto com os condicionantes naturais, destacam-se como fatores que ocasionam ou aceleram mudanças ambientais, comprometendo áreas de valor ecológico diversificado como restingas, manguezais, dunas e praias. Por outro lado, o processo de ocupação que quase nunca é acompanhado de um planejamento adequado, impulsiona problemas relacionados à restrição direta ou indireta do acesso a espaços destinados à coletividade.

Acompanhando essa realidade, o processo de ocupação da Ilha do Atalaia, Município de Salinópolis, Estado do Pará, influenciou a atuação de atores sociais cuja produção de processos espaciais se estruturam, desde o período colonial, ganhando dimensões complexas e contraditórias na segunda metade do século XX, o que ocasionou novas formas de relações sociais fundamentadas na reprodução desigual e desproporcional do espaço.

A Ilha do Atalaia revela, então, o aprofundamento de relações socioespaciais, decorrentes da difusão das formas de uso e apropriação do solo, as quais baseiam-se na conversão do espaço em mercadoria, entendendo-o como valor de troca, a partir da reprodução da lógica imposta por atividades como o veraneio marítimo e o turismo.

Neste sentido, a Ilha do Atalaia evidencia, como consequência do avanço de formas de apropriação e uso mais integradas à lógica do valor de troca, a produção de um espaço cada vez mais voltado para atender interesses econômicos, apresentando-se não somente danosa ao meio ambiente como constantemente induzindo conflitos com referência a ocupação.

Desta forma, o processo de apropriação sem os devidos cuidados legais da Ilha do Atalaia repercute em consequiências que estão materializadas no avanço das ocupações em Áreas de Preservação Permanente, no uso irregular privativo do espaço, na deficiência de saneamento básico, na reorganização do espaço em virtude da utilização do território por atores que o concebem como meio de reprodução do capital.

Todos esses fatores repercutiram em perdas significativas de seu potencial ambiental, culminando no baixo aproveitamento de seus recursos naturais e paisagísticos, tornando parte considerável dos atores sociais dependentes da sazonalidade das atividades de veraneio.

O presente trabalho refere-se à discussão sobre o uso do solo da Ilha do Atalaia, considerando, deste modo, as formas de apropriação diferenciadas, a partir da sua importância como espaço estratégico para a diversidade de atores sociais onde o uso que hoje se manifesta é fruto não apenas de uma apropriação "irregular", mas igualmente reflete a projeção espacial 
de interesses relativos aos recursos localmente identificáveis, o que repercute em sua organização socioespacial.

\section{BREVE ANÁLISE DO REGIME PATRIMONIAL NA ZONA COSTEIRA}

Antes de compreender o regime patrimonial costeiro, torna-se necessário destacar, inicialmente, que muitas definições de zona costeira já foram apresentadas, pois se sabe que esta é dinâmica no tempo e no espaço, não constituindo uma "unidade natural evidente" (MORAES, 2007, p. 30).

Dias (2003) afirma que as zonas costeiras correspondem a ecossistemas complexos, altamente dependentes de forçamentos externos (bacias hidrográficas, bacias oceânicas adjacentes, espaço atmosférico, parâmetros econômicos mundiais, tendências sociais, entre outros), compreendendo zonas estuarinas e lagunares, assim como litorais oceânicos.

A zona costeira, como interface biofísica e geoquímica entre o oceano, a terra e a biosfera, é uma área particularmente dinâmica com características biológicas, químicas, físicas e geológicas em constante transformação (CONSELHO NACIONAL DO AMBIENTE E DO DESENVOLVIMENTO SUSTENTÁVEL, 2001).

Sob aspecto jurídico, portanto, uma das definições mais completas e aplicáveis do ponto de vista do gerenciamento está apresentada na segunda versão do Plano Nacional de Gerenciamento Costeiro (PNGC II), já que inclui os limites político-administrativos como critério de delimitação da zona costeira.De acordo com esta definição, a zona costeira apresenta uma faixa marítima, correspondente a todo o mar territorial inserido na zona costeira, sendo o limite deste determinado pela Convenção das Nações Unidas sobre o Direito do Mar nas 12 milhas náuticas contadas da linha de base da costa e uma faixa terrestre, referente a todo o território dos municípios qualificados como costeiros a partir dos critérios estabelecidos no Plano (PROJETO ORLA, 2007). Moraes (2007) indica que esta nova definição da zona costeira ganhou uma conceituação "mais voltada para a prática do planejamento" (p. 116) cujo objetivo é justamente o planejamento e a gestão, o que evidencia "a importância de considerar os próprios limites político-administrativos como critério" (p. 115).

Diante dessas considerações a respeito da zona costeira, entende-se que nos espaços litorâneos brasileiros podem-se, então, encontrar diferentes regimes de propriedade, como 
bens particulares ou bens públicos. De acordo com a Constituição Federal de 1988, a propriedade de diversas espécies de bens que são verificados nos espaços litorâneos foi outorgada à união, sendo nessa faixa litorânea que se encontra situada uma parcela expressiva e relevante dos bens públicos nacionais (PROJETO ORLA, 2007).

Compreende-se que os bens públicos de uso comum da população são aqueles que, por determinação legal ou por sua própria natureza devem ser utilizados por todos em igualdade de condições, tais como ruas, praças, praias, rios, lagos, mar territorial e recursos naturais da zona econômica exclusiva e da plataforma continental. (art. 99 do C. Civil).

Redorat $(2010)^{2}$ ressalta que podem, então, ser destacados como bens da união: praias marítimas, terrenos de marinha e acrescidos, ilhas marítimas (oceânicas e costeiras) ${ }^{3}$, mar territorial, água e respectivos terrenos marginais e praias, manguezais, várzea, dentre outros.

A Constituição Federal de 1988 foi expressa, em seu artigo 20, inciso IV, em manter no patrimônio da União todas as ilhas marítimas (RODRIGUES, 2005). Seguindo este raciocínio, "não há razão para se entender que, então, as ilhas marítimas deixaram de compor o patrimônio público" (RODRIGUES, 2005, p. 01).Meirelles (2008), de forma objetiva e sintética afirma que "as ilhas costeiras, por se encontrarem no mar territorial, sempre foram consideradas domínio da União, porque este mar e tudo o que nele se encontra é bem federal" (MEIRELLES, 2008, p. 562).

É importante compreender, no entanto, que, freqüentemente, encontram-se bens da União que foram ocupados de forma irregular por empreendimentos de alta e média renda, sem autorização da SPU ou até mesmo do poder público local, o que propicia, frequentemente, irregularidades urbanístico-ambientais, como, por exemplo, os condomínios fechados que vedam o acesso público a praia, empreendimentos comerciais que ocupam a faixa de praia e hotéis que se instalam, sem licença, sobre os rios da região amazônica, ou seja, empreendimentos que ocupam bens da União sem autorização, licenciamento urbanístico ou ambiental (MRFU, 2006).

Em relação às Ilhas é válido ressaltar, então, que, segundo Bringhenti (2010) de interesse público não é apenas a conservação de seus atributos naturais, mas também seu uso

\footnotetext{
2Informação obtida na apresentação oral no workshop:Readaptação metodológica do Projeto Orla: orlas fluviais, estuarinas e marítimas da Amazônia Brasileira, Mosqueiro - PA, 22 a 24 de setembro de 2010.

3As ilhas marítimas estão classificadas em costeiras e oceânicas. As ilhas costeiras estão localizadas próximas ao continente, situadas no mar territorial.As ilhas oceânicas estão localizadas em alto- mar, afastadas da costa (MRFU, 2006).
} 
comum. Esta autora aponta que a Constituição Federal ao albergar no capítulo referente à ordem social, o princípio da preservação do meio ambiente como um direito de todos, sendo assegurado o franco e livre acesso a ele, denotou que o interesse público sobre estes bens não é só ambiental, mas socioambiental (art. 225, caput198). A partir desta lógica, “o interesse público sobre as ilhas costeiras assume dupla dimensão principiológica: o princípio da preservação ambiental e o princípio da igualdade de uso" (BRINGHENTI, 2010, p. 112).

Seguindo este pensamento, Bringhenti (2010) lembra que "o aspecto paisagístico assume relevância social e, portanto, de interesse público, porque é em função dele que nasce, o interesse coletivo de visitação sobre a ilha. E este interesse não é assegurado senão pelo direito de igualdade de uso" (p. 113, grifo do autor).

Assim, a supremacia do interesse público sobre o privado serve para tornar mais intensa a importância do princípio da preservação ambiental (aspecto ambiental) e do princípio da igualdade, o qual está relacionado ao aspecto social (BRINGHENTI, 2010).

Observa-se que tanto o interesse ambiental quanto social deve ser considerado, em paridade de condição, pois a sobreposição de um sobre o outro traria repercussões negativas para uma determinada ilha, no caso desta pesquisa, a Ilha do Atalaia.

\section{LOCALIZAÇÃO DA ÁREA DE ESTUDO}

O município de Salinópolis localiza-se na Mesorregião do Nordeste Paraense, Microrregião do Salgado (IBAMA, 2007), abrangendo uma área de aproximadamente 218 $\mathrm{km}^{2}$, limitada pelas coordenadas geográficas de $00^{\circ} 30^{\prime}$ e $01^{\circ} 00^{\prime}$ de latitude Sul e $47^{\circ} 00^{\prime}$ e $47^{\circ} 30^{\prime}$ de longitude W (BRITO, 2008).

A Ilha do Atalaia, apresenta uma superfície de $30 \mathrm{Km}^{2}$, sendo $12 \mathrm{~km}$ de linha de praia. Está distante cerca de $12 \mathrm{Km}$ da sede do município estando ligada a este através da estrada Salinópolis-Atalaia (carta imagem 1), construída sobre o rio Sampaio (MENDES et al., 1995). 


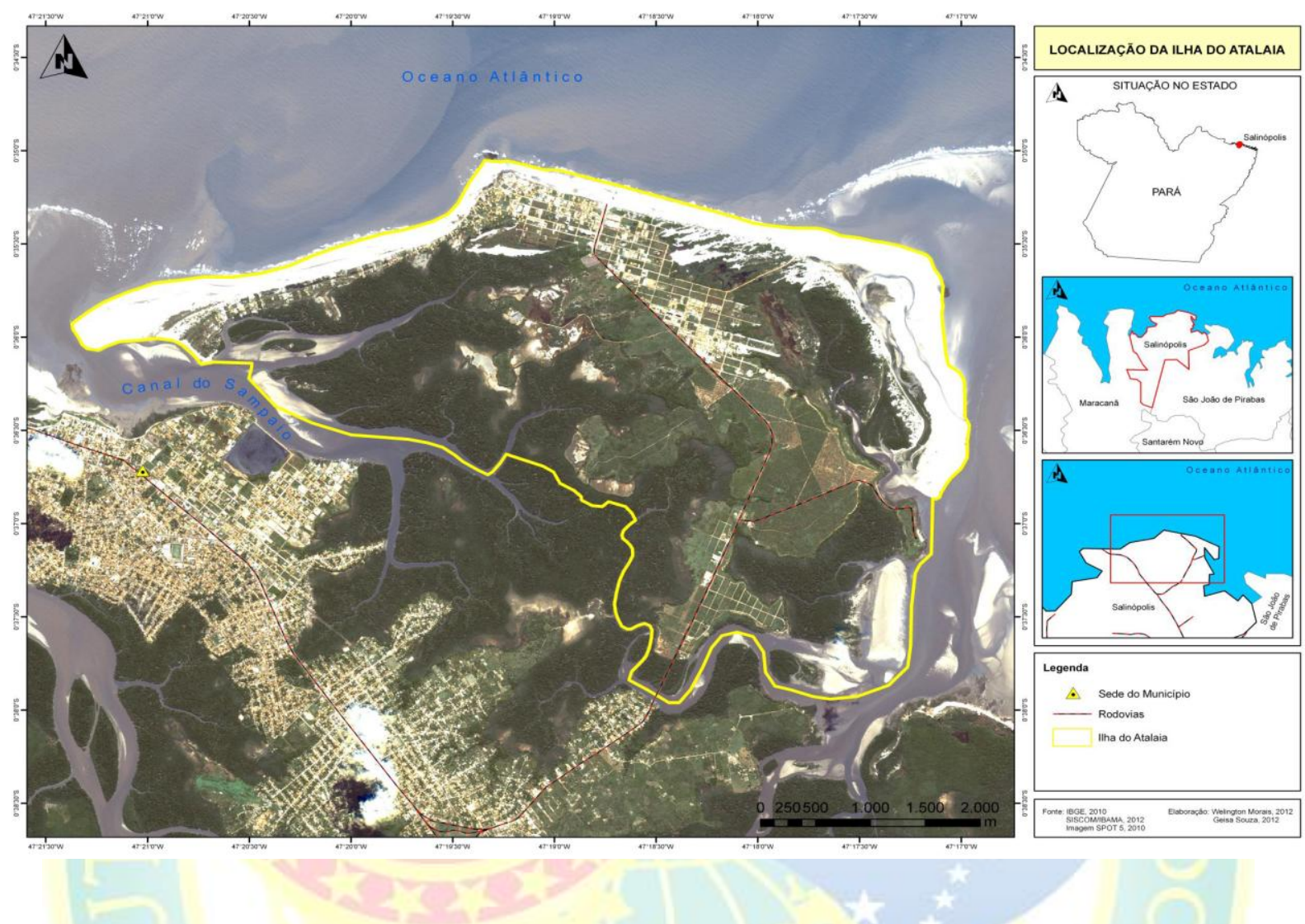

\section{O ACESSO DESIGUAL E DIFERENCIADO DA ILHA DO ATALAIA: OS TRECHOS DE OCUPAÇÃO}

Destaca-se, inicialmente, que a construção da estrada Salinópolis-Atalaia (assim como da ponte ligando a cidade à Ilha) funcionou como agente desencadeante do processo desorganizado de ocupação que se presencia na Ilha (BRITO, 2004), já que sua construção se deu antes das resoluções do Conselho Nacional de Meio Ambiente (CONAMA) (MENDES et al., 1995; BRITO, 2004). No entanto, a construção da estrada (sob a ótica das resoluções do CONAMA) deveria ter seguido as normas que garantissem a permanência de áreas de preservação, como é o caso dos mangues e faixas de migração de dunas (MENDES et al., 1995).

Foram identificados, neste trabalho, quatro trechos principais de ocupação, os quais são importantes do ponto de vista da gestão territorial. Estes trechos foram identificados a partir da atuação dos atores sociais e do uso que aí estabelecem. Cada um desses espaços apresenta, então, características ambientais, econômicas e legais peculiares, devendo as políticas de reordenamento considerar tais especificidades. 


\subsection{Trecho correspondente à praia do Farol Velho}

Apresenta como principal elemento a praia do Farol Velho, localizada ao lado esquerdo da estrada de acesso principal à praia. No entanto, abrange uma área além da faixa praial, a partir da coordenada $47^{\circ} 18^{\prime} 49,283^{\prime \prime} \mathrm{W}$ e $0^{\circ} 35^{\prime} 33,061$ ' S no sentido Leste - Oeste, estendendo-se até a coordenada $47^{\circ} 21^{\prime} 20,28^{\prime \prime} \mathrm{W}$ e $0^{\circ} 36^{\prime} 18,01$ "S. Caracterizada pela presença de loteamentos com edificações, este trecho sofreu descaracterização de seu ambiente devido à ocupação dessas construções em áreas de falésias ativas, e em áreas de restingas, fatores que evidenciam a presença de problemas de natureza ambiental e legal nesse espaço.

Apresenta como principais usos a segunda residência, o comércio, hotéis e pousadas, as instituições públicas (municipais) e, em número reduzido, confecção e venda de artesanato. A ocupação da praia do Farol Velho não se desenvolveu de modo ordenado, acentuando o risco geológico provocado pela erosão costeira, fazendo com que os proprietários das segundas residências iniciassem um ciclo de construção de muros de contenção (MENDES, e PEREIRA, 2005). É um trecho que concentra residências de alto valor imobiliário, que atendem uma população de segunda residência proveniente, principalmente, da capital do Estado ao mesmo tempo em que abarca a maior quantidade de população residente da ilha, estimada em 195 famílias4.

Conforme o relatório de Estudos Florísticos (IBAMA, 2007), a praia do Farol Velho apresenta duas zonas diferenciadas pelo grau de urbanização que apresentam. A zona entre a estrada de acesso à praia do Atalaia e o ramal de acesso principal à área do Farol Velho,caracteriza-se por um avançado processo de urbanização, enquanto que a zona localizada a esquerda do ramal de acesso principal à praia do Farol Velho, a urbanização é menos intensa. No entanto, para este trabalho considerou-se esse trecho em sua integralidade, já que nas duas zonas a ocupação aconteceu de forma desorganizada.

\subsection{Trecho referente à praia do Atalaia}

Assim como o trecho anterior, este trecho não se refere apenas à faixa praial, no entanto a referência é a praia do Atalaia, caracterizada como a principal atração turística da Ilha. Considerou-se, então, neste trecho a extensão localizada a direita da estrada de acesso

4 Dados de dezembro de 2011, obtidos na Secretaria de Saúde do Município de Salinópolis. 
principal à praia (estrada Salinópolis-Atalaia) até a última barraca comercial, a partir da coordenada $47^{\circ} 18^{\prime} 43,147^{\prime}$ W e $0^{\circ} 35^{\prime} 16,752^{\prime}$ ' S no sentido Oeste - Leste até a coordenada $47^{\circ} 17^{\prime} 38,183$ ' W e $0^{\circ} 35^{\prime} 39,517^{\prime}$ 'S.

Conhecida pela presença de barracas de palafitas de uso comercial e residencial (dependendo do caso), entrada intensa de veículos, presença de veranistas e turista, caracteriza-se pela marcante dinâmica econômica e acumula uma grande quantidade de problemas ambientais e legais, devido sua forma de ocupação desorganizada. As ocupações presentes na faixa praial deste trecho não possuem titulação reconhecida pela Gerência de Patrimônio da União - GRPU/PA, apresentando atividades que ameaçam o meio ambiente e, até 2007, registravam-se eventos que privatizavam trechos da praia em detrimento do uso livre e desimpedido (TAC, 2007).

Tais fatores mostraram a necessidade de medidas legais mais concretas no controle do uso desse espaço, o que culminou com o acordo entre a União, a prefeitura do Município, o Estado do Pará e os proprietários, usufrutuários, locatários e ocupantes das barracas através do Termo de Ajuste de Conduta (TAC). Assim,

O Termo de Ajuste de Conduta tem por objetivo a proteção do meio ambiente, o ordenamento das ocupações e o uso do solo e recursos naturais relativos a Áreas de Preservação Permanente e de áreas de uso comum do povo localizadas na praia do Atalaia, no Município de Salinópolis/Pará (TAC, 2007).

Das 84 barracas presentes na praia do Atalaia, 72 assinaram o Termo de Ajuste de Conduta5. É válido destacar que a adesão ao TAC, não representa transferência dominial, nem direito adquirido ao uso de bem da União (TAC, 2007).

Mas não são apenas os barraqueiros que atuam neste trecho (já que vai além da faixa praial), outros atores sociais fazem-se presentes como os comerciantes, os donos de hotéis e pousadas e a população de segunda residência. Este trecho apresenta também loteamentos e edificações, muitas vezes em área de Área de Preservação Permanente, o que intensifica seus problemas de natureza ambiental e legal.

\subsection{Trecho referente ao rancho dos pescadores}

O trecho inicia sob as coordenadas $47^{\circ} 17^{\prime} 36,724^{\prime \prime} \mathrm{W}$ e $0^{\circ} 35^{\prime} 40,532^{\prime \prime} \mathrm{S}$ e se estende até as coordenadas $47^{\circ} 17^{\prime} 22,528^{\prime \prime} \mathrm{W}$ e $0^{\circ} 36^{\prime} 1,298^{\prime \prime} \mathrm{S}$ no sentido Leste - Sul. Este trecho 
está caracterizado como praia ocupada por população tradicional. Esse tipo de praia caracteriza-se por ser "pouco ocupada, com habitações rústicas, população pequena e semiisolada, atividades de subsistência predominantes, gêneros de vida tradicionais, presença de vegetação original, baixo antropismo da paisagem, contaminação baixa ou inexistente" (PROJETO ORLA, 2007, p. 40).

$\mathrm{Na}$ praia dos pescadores, também conhecida como praia da Sofia, apresenta-se a colônia de pescadores, onde é praticada a pesca para a subsistência. Este território era ocupado, em 2007, por 25 famílias6. Em 2010 este trecho estava sendo ocupado, em média, por 15 famílias 7 . No entanto, os que moram definitivamente, estão em número bastante reduzido. Apenas 02 famílias têm barco de pesca e vivem dessa atividade, o restante tem outras fontes de sobrevivência e não moram permanentemente neste trecho8. Então, conforme a SPU, o rancho dos pecadores é temporário, assim, não se faz levantamento.

De acordo com entrevista à Secretaria de Meio Ambiente de Salinópolis e à SPU este trecho é visto como parte da praia do Atalaia. Neste trabalho, entretanto, está sendo considerado separadamente devido às diferenças e particularidades que apresenta. É a área com menor grau de ocupação da ilha, apresenta menor índice de degradação ambiental e recebe poucos visitantes.

Quanto à questão da regularização, de acordo com entrevistas à SPU, a intenção é respeitar as comunidades e ocupações tradicionais, incluindo o rancho dos pescadores. Para tal, faz-se necessário um diagnóstico físico-territorial e sócio-econômico desse espaço por meio de metodologia já desenvolvida pela Secretaria do Patrimônio da União. Se for umasituação real de ocupação de área pública a SPU buscará o reconhecimento da posse. Mas se houver o comprovamento de que são pescadores não haverá interesse em removê-los9.

\subsection{Centro da Ilha}

Esse trecho refere-se a todo o espaço restante da ilha, compreendendo uma área de 1427,5340 hectares. É caracterizado, principalmente, pela existência de imóveis não

6 Informação obtida na SPU em entrevista realizada em 25 de abril de 2011

7 Informação obtida em entrevista aos barraqueiros em 23 de novembro de 2010.

8 Entrevista realizada na SPU em 25 de abril de 2011.

9 Informações obtidas em entrevista com o Superintendente do Patrimônio da União, Lélio da Costa Silva, em 28 de abril de 2011. 
construídos, apresentando empreendimentos agroindustriais como a plantação de coco que corresponde a uma área de 296,2078 hectares.

Apresenta também uma área construída, assim como loteamentos postos a venda (principalmente referente ao Residencial Raízes), o que indica a expansão da urbanização no sentido sul da Ilha, a partir da atuação de proprietários fundiários e do mercado imobiliário. Observa-se reduzido número de estabelecimentos comerciais. Este trecho está representado em maior parte pelas terras denominadas Cocal (referente à área agrícola), encontrando-se também vegetação de mangue.

É válido enfatizar que, quando se considera o centro da Ilha, neste trabalho, não se pretende discriminar a ilha em terreno de marinha e parte nuclear, do ponto de vista jurídico, já que a ilha em sua integralidade deveria pertencer ao poder público. Os trechos de ocupação e uso da Ilha do Atalaia, podem ser observados na carta imagem 2.

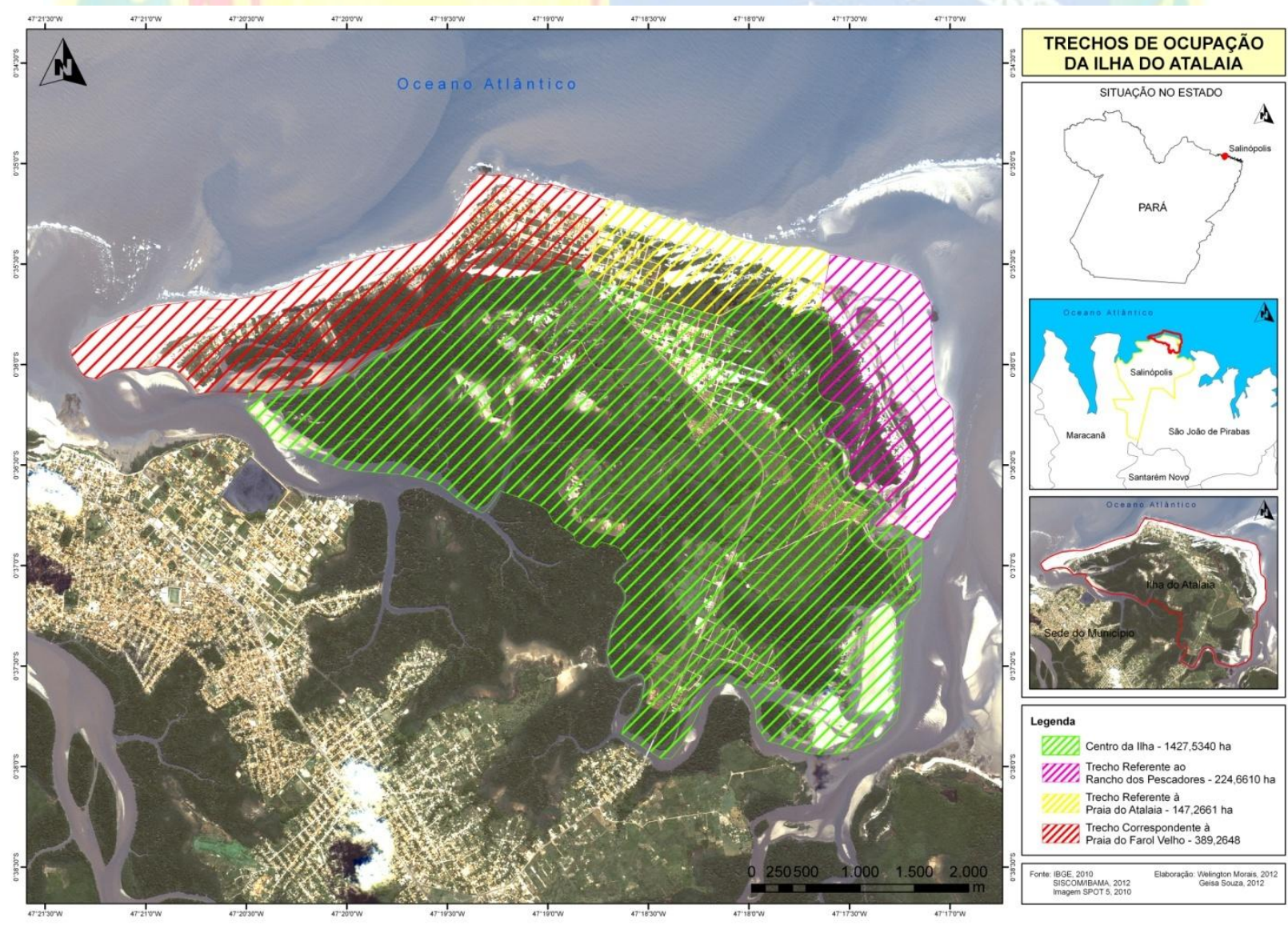




\section{ANÁLISE DO ORDENAMENTO TERRITORIAL NA ILHA DO ATALAIA}

O ordenamento territorial é um conceito ainda em construção, sendo objeto de várias interpretações e com grande variação de concepções quanto à sua natureza (BECKER, 2005). Trata-se, então, de um conceito "impreciso e polissêmico. O seu processo de construção, obviamente, reflete os diversos processos diferenciados das experiências de políticas de ordenamento territorial" (RÜCKERT, 2005, p. 35).

Para Moraes (2005) ordenamento territorial deve ser pensado como aquele que busca captar os grandes padrões de ocupação, as formas predominantes de valorização do espaço, os eixos de penetração do povoamento e das inovações técnicas e econômicas e a direção prioritária dos fluxos, objetivando estabelecer um diagnóstico geográfico do território, indicando tendências e aferindo demandas e potencialidades, de maneira a compor o quadro no qual devem operar de forma articulada as políticas públicas setoriais, com vistas a realizar os objetivos estratégicos do governo.

Este mesmo autor afirma que o ordenamento territorial é um instrumento de articulação transetorial e interinstitucional, cujo objetivo é um planejamento integrado e especializado da atuação do poder público, compatibilizando políticas públicas, em que o estado é um agente regulador e harmonizador.

O ordenamento territorial apresenta, portanto, uma variedade de conceitos e abundância de conteúdo, mas como pode ser percebido diante dos conceitos aqui apresentados, geralmente, o entendimento do que é o ordenamento territorial está relacionado ao ordenamento da ocupação, dos usos múltiplos do território e, consequentemente, de seus recursos naturais.

A análise do ordenamento territorial referente à Ilha do Atalaia a partir dos trechos destacados demonstra desigualdades no uso, assim como a diversidade da função dos atores no processo de funcionamento do espaço da ilha, cuja ocupação realizou-se a partir de um ordenamento que se encontra em desacordo com a legislação.

Entende-se que parcela da população local não é incorporada ao usufruto desse espaço, onde se desenvolveu um pensamento de posse, assim como de despreocupação ambiental. Soma-se a este pensamento, a ideia de atender uma população de fora do município. 
Lotes são vendidos a preços altos àqueles, cuja situação econômica permite pagar por eles. Assim, o veraneio e o turismo dão prioridade às pessoas de alta renda. Nota-se, então, uma situação em que ou se é "proprietário" (apropriação do espaço) ou se pode pagar pela terra (compra de lotes) ou pelo serviço (restaurantes, hotéis, pousadas, aluguéis), enquanto grande parcela da população não usa um espaço que, por lei, é público e coletivo (princípio da igualdade), o que indica seu usufruto limitado.

Nestes termos o acesso à Ilha, em determinados trechos, torna-se prioridade daqueles que desenvolveram uma territorialidade dada sua condição econômica. É imprescindível, então, compreender que na medida em que se concebe os espaços estuarinos como espaços públicos são passíveis de implementação de um reordenamento territorial que possibilite um acesso menos desigual e menos desproporcional aos recursos naturais e paisagísticos da Ilha do Atalaia.

Neste sentido, pode-se afirmar que a Ilha do Atalaia sofre com a deficiência ou inexistência das políticas de ordenamento territorial interessadas em organizar o espaço, de maneira eficaz e coerente com a realidade existente, pois se percebeu que no que se refere às dimensões ambiental e legal o processo de ocupação da Ilha do Atalaia, mostra evidências da apropriação particular de espaços públicos, cujas atividades desenvolvidas muitas vezes estão desligadas da preocupação ambiental.

\section{CONSIDERAÇÕES FINAIS}

Identificou-se que a produção do espaço na Ilha do Atalaia aponta para um movimento de reprodução diversificada, levando a problemas de natureza ambiental e social, o que repercute em contradições que são observadas no uso desigual por seus atores sociais.

Assim, constatou-se que muitos problemas são provenientes da forma de apropriação e uso do solo da Ilha do Atalaia, podendo ocasionar outros problemas futuros a seus diversos atores sociais, uma vez que a ocupação da Ilha ocorreu sem a infraestrutura suficiente ou adequada implantada de forma a contrariar a legislação ambiental, o que resultou na degradação natural, paisagística e econômica da Ilha.

A forma de ocupação, então, propiciou a exploração da Ilha do Atalaia não só pelas atividades de veraneio e turismo, mas também pela atividade imobiliária, as quais estão 
interconectadas, restringindo direta ou indiretamente determinados atores sociais do usufruto de recursos naturais e paisagísticos.

Observou-se que para atender a uma população de segunda residência e promover atividades de veraneio, o Estado produziu e induziu um conjunto de práticas relacionadas principalmente a intervenções em infraestrutura básica, o que ocasionou a partir das últimas décadas (mais especificamente a década de 1980) uma nova reorganização socioespacial na Ilha do Atalaia, assim como em todo o município de Salinópolis.

Daí considerar e até mesmo evidenciar as peculiaridades e complexidades de sua organização espacial e territorial. Assim, a Ilha do Atalaia é um espaço de apropriação de diferentes atores sociais, o que resultou na produção de espaços distintos. A forma dos atores se relacionarem entre si e/ou com o espaço acumulou-se de maneira diferenciada no decorrer do tempo, culminando em territorialidades também diversificadas no espaço da ilha.

As formas espaciais criadas por seus atores sociais ao longo do processo de produção do espaço, pode ser constatado nos diferentes trechos de ocupação mostrados neste trabalho, os quais exigem tipos diferentes de gestão. Considerando, desse modo, a diversidade espacial da Ilha do Atalaia, as dinâmicas sociais e ambientais também acompanham as especificidades encontradas em cada trecho.

Torna-se complicado elaborar um plano de gestão e reordenamento em um espaço, cuja dinâmica territorial apresenta características tão diversas, o que mostra a necessidade da adequação a cada trecho de ocupação, sendo a fiscalização permanente uma ferramenta importante nas políticas de gestão, uma vez que busca organizar racionalmente o espaço, a partir de medidas de prevenção e controle.

Já que os atores sociais se espacializam de forma diferenciada, um ordenamento do território deve ser capaz de garantir uma gestão criteriosa de recursos, em benefício dos espaços e dos atores sociais aí presentes, observando atentamente as especificidades de cada realidade e aproveitando suas identidades. 


\section{REFERÊNCIAS BIBLIOGRÁFICAS}

BECKER, Bertha. K. Síntese geral sobre política nacional de ordenamento territorial. In: Para pensar uma política nacional de ordenamento territorial: anais de oficina sobre a política nacional de ordenamento territorial, Brasília, 13-14 de novembro de 2003/ Ministério da Integração Nacional, Secretarias de Políticas de Desenvolvimento Regional / SDR- Brasília: MI, 2005, p. 71-78.

BRASIL. Secretaria do Patrimônio da União. Ministério do Planejamento, Orçamento e Gestão. Manual de Regularização Fundiária em Terras da União. Brasília: SPU, 2006. 128p.

BRINGHENTI, Priscila. A (in) constitucionalidade da regularização de ocupações privativas de ilhas costeiras brasileiras. Universidade comunitária da região de Chapecó - unochapecó. Trabalho de Conclusão de Curso. Chapecó (SC), 2010. 181p.

BRITO, Francinete Maria Oliveira de. Salinópolis-Pa: (re) organização sócio-espacial de um lugar atlântico-amazônico. Florianópolis: UFSC (Dissertação de Mestrado), 2004. 121p.

BRITO, Francinete Maria Oliveira de. O turismo em um lugar atlântico-amazônico: recentes alterações sócio-espaciais. Scripta Nova. Reviste Eletrônica de Geografia y Ciências Sociales. Barcelona: Universidade de Barcelona, 1 de agosto de 2008, vol. XII, num 270.90.> htttp://WWW.ub.es/geocrit/Sn/Sn.270/Sn-270-90.htm > [ISSN:1138-9788]. Acesso em $17 \mathrm{de}$ julho de 2011.

CÓDIGO Civil. Capítulo III- Dos bens da União. Lei n 10.406, de 10 de janeiro de 2002. (disponível em http:// www.planalto.gov.br). Acesso em 16 de julho de 2011.

CONSELHO Nacional do Ambiente e do Desenvolvimento Sustentável (Órgão independente criado pelo Decreto-Lei ${ }^{\circ} 221 / 97$, de 20 de Agosto, DR I-A n¹51) Reflexão sobre o desenvolvimento sustentável da zona costeira. Portugal, 2001. 53p.

DIAS, João M. Alveirinho. Gestão integrada das zonas costeiras: mito ou realidade? II congresso sobre planejamento e gestão das zonas costeiras dos países de expressão portuguesa IX Congresso da Associação Brasileira de Estudos do Quaternário. II Congresso do Quaternário dos Países de Línguas Ibéricas. Recife, 2003. 5p.

IBAMA. Instituto Brasileiro do Meio Ambiente e dos Recursos Naturais Renováveis. Perícia de estudos florísticos na praia do Farol Velho, no município de Salinópolis/PA. Serviço Público Federal, Ministério do Meio Ambiente. Superintedência do Estado do Pará, 2007.

MEIRELLES, Helly Lopes. Direito administrativo brasileiro. MALHEIROS. $34^{\circ}$ ed. São Paulo, 2008.

MENDES, Amílcar Carvalho. FARIA JR, Luís Ercílio do C. SILVA, Márcio Souza. Laudo pericial sobre os impactos ambientais na ilha do Atalaia-município de Salinópoles/Pará. Universidade Federal do Pará-PROMAR. Belém, 1995. 41p. 
MENDES, Amílcar Carvalho e PEREIRA, Moacir José. Uso e ocupação da faixa praial da Ilha do Atalaia-Salinópoles (PA). Uso e apropriação de recursos costeiros (RECOS). Instituto do milênio. Belém, 2005. 45p.

MORAES, Antônio Carlos Robert. Ordenamento territorial: uma conceituação para o planejamento estratégico. In: Para pensar uma política nacional de ordenamento territorial: anais de oficina sobre a política nacional de ordenamento territorial, Brasília, 13-14 de novembro de 2003/ Ministério da Integração Nacional, Secretarias de Políticas de Desenvolvimento Regional-SDR- Brasília: MI, 2005, p. 43-47.

Contribuições para a gestão da zona costeira no Brasil: elementos para uma geografia do litoral brasileiro. São Paulo: Annablume, 2007.

PROJETO ORLA. Subsídios para um projeto de gestão. Ministério do Meio Ambiente, Ministério do Planejamento, Orçamento e Gestão, Brasília: MMA, 2007. 103p.

REDORAT, Reinaldo. MINISTÉRIO DO PLANEJAMENTO, ORÇAMENTO E GESTÃO Secretaria do Patrimônio da União - SPU Coordenação-Geral de Apoio ao Desenvolvimento Local. WORKSHOP de Readaptação metodológica do Projeto Orla: Orlas fluviais, estuarinas e marítimas da Amazônia Brasileira, Mosqueiro - PA, 22 a 24 de setembro de 2010.

RODRIGUES, Ricardo Wey. A propriedade privada nas ilhas costeiras brasileiras. Jus Navigandi, Teresina, ano 10, n. 705, 10 jun. 2005. Disponível em: <http://jus.com.br/revista/texto/6861>. Acesso em: 13 janeiro de 2012.

RÜCKERT, Aldomar Arnaldo. Processo de reforma do estado e a política nacional de ordenamento territorial. In: Para pensar uma política nacional de ordenamento territorial: anais de oficina sobre a política nacional de ordenamento territorial, Brasília, 13-14 de novembro de 2003/ Ministério da Integração Nacional, Secretarias de Políticas de Desenvolvimento Regional-SDR- Brasília: MI, 2005, p. 31-39.

TAC. Termo de Ajuste de Conduta. Advocacia Geral da União, Procuradoria da União do Estado do Pará, 2007. 